\title{
Adsorption/desorption properties of copper ions on the surface of iron-coated sand using BET and EDAX analyses
}

\author{
C.H. Lai ${ }^{a, *}$, S.L. Lo ${ }^{\text {b }}$, H.L. Chiang ${ }^{\text {a }}$ \\ a Department of Environmental Engineering and Sanitation, Fooyin Institute of Technology, 151 Ching-Hsueh Road, Ta-Liao Hsiang, \\ Kao-Hsiung Hsien 831, Taiwan, ROC \\ ${ }^{\mathrm{b}}$ Graduate Institute of Environmental Engineering, National Taiwan University, 71 Chou-Shan Road, Taipei 106, Taiwan, ROC
}

Received 29 September 1999; accepted 5 November 1999

\begin{abstract}
This study was conducted to develop a heating process for coating hydrated iron oxide on the sand surface to utilise the adsorbent properties of the coating and the filtration properties of the sand. BET and scanning electron microscope (SEM) analyses were used to investigate the surface properties of the coated layer. An energy dispersive X-ray (EDAX) technique of analysis was used for characterising metal adsorption sites on the iron-coated sand surface. The results indicated that the iron-coated sand had more micropores and higher specific surface area because of the attachment of iron oxide. Copper ions could penetrate into the micropores and mesopores of iron oxide on sand surface, and the regeneration of the iron-coated sand could be achieved by soaking with $\mathrm{pH}=3.0$ acid solution. Besides, the results of EDAX analysis showed that copper ions were chemisorbed on the surface of iron-coated sand. Results of the study developed an innovative technology for coating iron oxide on sand surface for the treatment of heavy metal in water. (c) 2000 Elsevier Science Ltd. All rights reserved.
\end{abstract}

Keywords: Adsorption; Copper; EDAX; Iron oxide; Pore size distribution

\section{Introduction}

In recent years, many researchers have applied iron oxide to the adsorption of heavy metals from metalbearing tap or waste water. Adsorption is capable of removing metals over a wider $\mathrm{pH}$ range and lower concentrations than precipitation (Benjamin and Leckie, 1981; Schwertmann and Taylor, 1989). Most iron oxides are available only as fine powders or are generated in aqueous suspension as hydroxide floc or gel. In such forms, these oxides retain their desirable adsorptive

\footnotetext{
${ }^{*}$ Corresponding author. Tel.: +886-7-781-1151; fax: +886-7782-1221.

E-mail address: p1011@mail.fy.edu.tw (C.H. Lai).
}

properties for the trace metals, but they are limited to reactor configurations incorporating with large sedimentation basins or filtration unit. Under such conditions, the solid/liquid separation is fairly difficult. Besides, iron oxide alone is not suitable as a filter medium because of their low hydraulic conductivity (Theis et al., 1992).

Recently, some researchers have developed the techniques for coating iron oxide on sand surface to overcome the problem of using iron oxide powders in water treatment process. Iron-coated sands have been tested for removing of cations and anions from synthetic and real wastes (Edwards and Benjamin, 1989; Bailey et al., 1992; Lai et al., 1994a,b; Satpathy and Chaudhuri, 1995; Benjamin et al., 1996; Lo et al., 1997). The results from their studies confirm that the utilisation of iron-coated sand is worth developing for metal ions removal from water. 
The study investigated the coating technology of iron oxide on the sand surface to use in water treatment. BET and SEM/EDAX techniques of analysis were employed to investigate the properties of adsorption/desorption reactions for copper ions on the iron-coated sand surface in water. Results provide fundamentals of adsorption/desorption properties for the use of iron-coated sand.

\section{Materials and methods}

\subsection{Coating process}

Stock solution of $0.5 \mathrm{M} \mathrm{Fe(III)} \mathrm{was} \mathrm{prepared} \mathrm{by}$ dissolving $\mathrm{Fe}\left(\mathrm{NO}_{3}\right)_{3} \cdot 9 \mathrm{H}_{2} \mathrm{O}$ in Milli-Q water. The diametre of the sand ranged 16-25 mesh $(0.67$ to $0.99 \mathrm{~mm})$. The sand was soaked in acid solution $(\mathrm{pH}=1.0, \mathrm{HCl})$ for $24 \mathrm{~h}$, rinsed with deionised water, and dried at $103 \pm 2^{\circ} \mathrm{C}$. To coat the sand using $100 \mathrm{ml}$ of stock solution, base was added by dropwise addition of $5.0 \mathrm{~N}$ $\mathrm{NaOH}$ until a $\mathrm{pH}$ of $9.5 \pm 0.1$ was attained, and the solution continued to mix $5 \mathrm{~min}$. The solution of iron oxide and $200 \mathrm{~g}$ sand were poured in a 1 liter glass beaker. The mixture was placed in a drying oven at $50 \pm 1{ }^{\circ} \mathrm{C}$ for $96 \mathrm{~h}$, and it was stirred by a teflon mixer during the first $24 \mathrm{~h}$. After that, the iron-coated sand was washed with de-ionised water until run-off was clear, then redried at $50 \pm 1^{\circ} \mathrm{C}$ for $96 \mathrm{~h}$, and finally stored in polystyrene bottles for further uses.

\subsection{Mineral identification}

The mineralogy of the iron oxide and the sand were characterised by X-ray diffraction (X-ray Tokyo Shibaura, Model ADG-301E, X-ray Diffraction Metre, XRD), respectively. Operation parameters were as follows: $\mathrm{Cu} \mathrm{K} \mathrm{K}_{\alpha}$ radiations at $30 \mathrm{kV}$ and $20 \mathrm{~mA}$. The samples were scanned from $10^{\circ}$ to $70^{\circ}, 2 \theta$, and the scanning rate was fixed at $0.05^{\circ}, 2 \theta / \mathrm{s}$.

\subsection{Adsorption/desorption experiments}

Batch adsorption equilibrium experiments were conducted by equilibrating an accurately weighed $2.5 \mathrm{~g}$ iron-coated sand with $50 \mathrm{ml}$ of copper ion solutions of known concentrations. Initial concentrations of copper ions were held to $0.64 \pm 0.05,3.20 \pm 0.05$ and $6.40 \pm$ $0.05 \mathrm{mg} / 1$. The $\mathrm{pH}$ of $6.0 \pm 0.1$ was maintained throughout the experiments using dilute $\mathrm{HNO}_{3}$ and $\mathrm{NaOH}$ solutions. Constant stirring of the solution was maintained using a water bath shaker. All the operations were conducted at $25 \pm 1{ }^{\circ} \mathrm{C}$. $\mathrm{NaNO}_{3}$ was added to adjust the background ionic strength to $0.1 \mathrm{~N}$, the $\mathrm{pH}$ range of solution was from 3.0 to 6.5 , and the contact time was $3 \mathrm{~h}$. After attainment of equilibrium, the contents of the flask were filtered through $0.2 \mu \mathrm{m}$ cellulose nitrate membrane filters. Residual concentration of metal was determined by flameless atomic absorption spectrophotometry (Perkin-Elmer A310). The desorption rates experiments were conducted serially on previously equilibrated samples under adsorbing conditions for $0.5-24 \mathrm{~h}$ rapidly changing the solution $\mathrm{pH}$ to $3.0 \pm 0.1$, and the reaction time lasted $1440 \mathrm{~min}$. Samples were taken as before.

Besides, the samples of iron-coated sand for BET and EDAX analyses were prepared by the same procedure of above. After $3 \mathrm{~h}$ of adsorption, they were eluted several times with Milli-Q water until the electric conductivity of supernatant of samples was approximately equal to that of Milli-Q water. Freezing dry procedures were used for drying the solid samples.

\subsection{Specific surface area and pore size distribution analyses}

Analyses of physical characteristics of the sand and iron-coated sand included SEM observations, BET specific surface area, micropore volume and pore size distributions. A photomicrography of exterior uncoated and iron-coated sand surface was obtained by SEM (Hitachi-S-2400, Japan). For the purpose of observing the surface of iron-coated sand easily, the cubical sand was selected. The front side of the sample was polished by No. 800-1200 SiC sand-papers. The other characteristics were determined by the nitrogen adsorption isotherm technique, with an ASAP 2000 micropore analyser (Micromeritrics USA). The nitrogen adsorption was carried out at $77 \mathrm{~K}$.

\subsection{SEM/EDAX analysis}

Samples for SEM/EDAX (Hitachi-S-2400 Scanning Electronic Microscope with an EDAX KEVEX Level 4) analysis were coated with thin carbon film in order to avoid the influence of charge effect during the SEM operation. Elemental micro-probe and elemental distribution mapping techniques were used for analysing the elemental constitution of solid samples. The scanning energy for EDAX analysis was from 0 to $10.23 \mathrm{keV}$ with an elapsed time of $100 \mathrm{~s}$.

\section{Results and discussion}

\subsection{Mineral identification}

The mineralogy of the sand and iron oxide was determined by X-ray diffraction. The data published by the 
joint committee on powder diffraction standards (JCPDS) were used to identify the crystalline phases. The sand turned out to be exclusively quartz (JCPDS pattern number: 33-1161). Iron oxide prepared by coating procedure was verified to be the crystalline goethite (JCPDS pattern number: 29-713).

\subsection{Mineralogy of iron-coated sand}

SEM photographs in Fig. 1 were taken at 5000X, $10000 \mathrm{X}$ magnifications to observe the surface morphology of the quartz sand and iron-coated sand, respectively. Quartz sand had a very rough surface and cracks, macropores or roughness could be found on the sand surface. On the contrary, the iron-coated sand appeared as uniformly coated surface. Quartz sand surfaces were apparently occupied by iron oxides, which were formed during the coating process. No cracks were visible, except for the crystalline iron oxides found on the surface. The microstructure from the sample of polished iron-coated sand is shown in Fig. 2. It could be found the sand surface was covered with iron oxide particles by the SEM observation, and the coating thickness of iron oxide was about 4-7 $\mu \mathrm{m}$. The amount
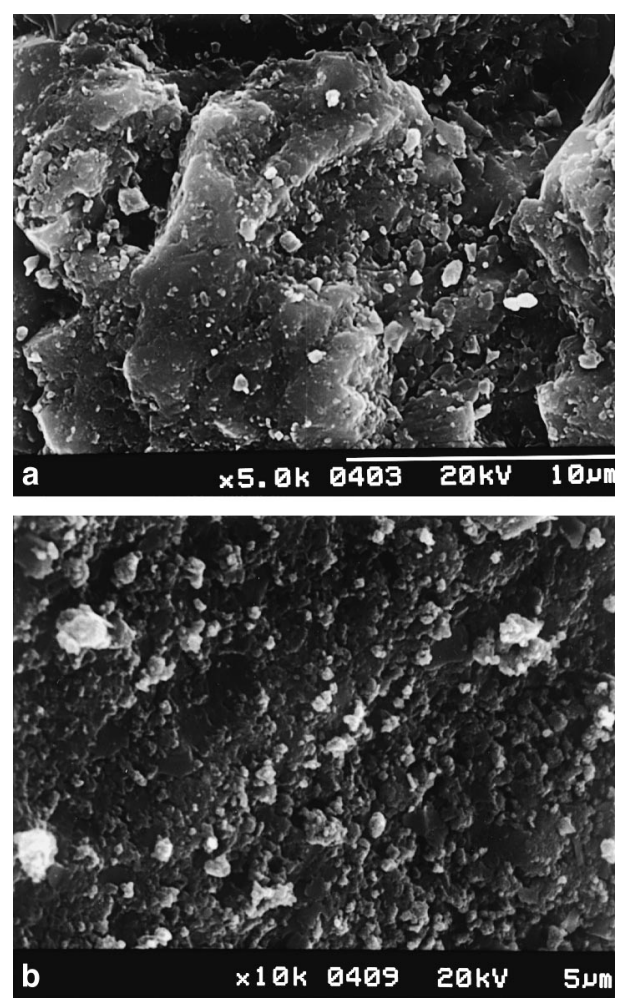

Fig. 1. SEM micrographs of sample: (a) quartz sand; (b) ironcoated sand. of iron on the sand surface was about $5.7 \pm 0.3 \mathrm{mg}$ $\mathrm{Fe} / \mathrm{g}$-sand by acid digestion analysis.

\subsection{Adsorption experiments}

Copper ions can firmly adsorb to the interface of water/iron-coated sand. The results are illustrated in Fig. 3. The adsorption of copper increases with increasing solution $\mathrm{pH}$ or high surface loading. The interface of water/iron-coated sand can provide sufficient adsorption sites for metal ions, the copper adsorption density, thus, increase with higher surface loading. The adsorption concentration on iron-coated sand surface increases as copper concentration increases. If surface loading exceeds adsorption sites which will be provided by the interface of water/iron-coated sand, the adsorption quantity of copper would be maintained a constant value, and the adsorption efficiency cannot be enhanced. The adsorption sites of iron-coated sand can be enhanced, the adsorption of metal ions should be increased. Therefore, increasing the density of adsorption

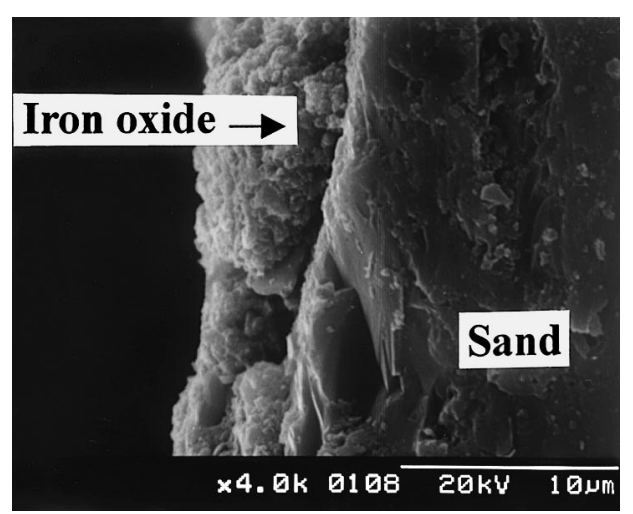

Fig. 2. SEM micrograph of the interface for polishing iron-coated sand.

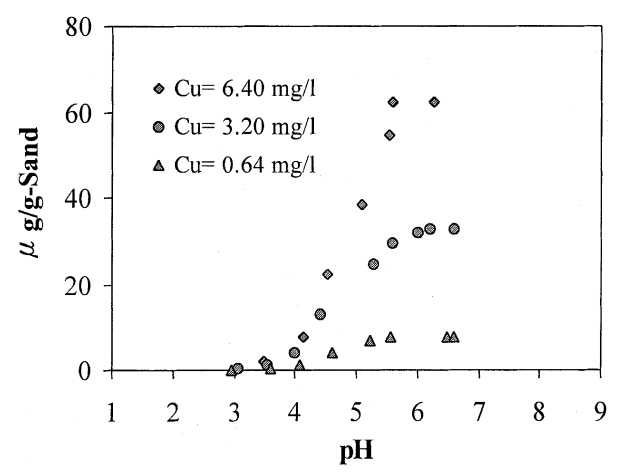

Fig. 3. Adsorption density for copper on $2.5 \mathrm{~g}$ iron-coated sand under $\mathrm{NaNO}_{3}=0.1 \mathrm{~N}, \mathrm{Cu}_{(\mathrm{t})}=6.40,3.20,0.64 \mathrm{mg} / \mathrm{l}$. 
sites on iron-coated sand surface should be the objective of coating technique studies in the future.

Results of adsorption density experiments were listed in Table 1. The equilibrium adsorption constant and maximum adsorption capacity for $\mathrm{pH}=6.0$ were computed by Langmuir equation as

$Q=Q_{\mathrm{m}} \cdot K C /(1+K C)$

where $C(\mathrm{mg}-\mathrm{Cu} / \mathrm{l})$ is the concentration of copper in solution, $Q$ ( $\mu \mathrm{g}-\mathrm{Cu} / \mathrm{g}$-sand) is the adsorbed density of copper per mass of iron-coated sand, $Q_{\mathrm{m}}$ ( $\mu \mathrm{g}-\mathrm{Cu} / \mathrm{g}$-sand) is the maximum adsorption capacity, $K(1 / \mathrm{mg}-\mathrm{Cu})$ is the equilibrium adsorption constant. The comparisons of the data between simulation and experiment are illustrated in Fig. 4. The Langmuir equation is shown as

$Q=57.89 C /(1+0.268 C)$

The equilibrium adsorption constant $(K)$ and maximum adsorption capacity $\left(Q_{\mathrm{m}}\right)$ values are $0.2681 / \mathrm{mg}-\mathrm{Cu}$ and $216 \mu \mathrm{g}-\mathrm{Cu} / \mathrm{g}$-sand, respectively.

\subsection{Desorption experiments}

The kinetics data of desorption for the various contact time of adsorption are illustrated in Fig. 5. The desorption rate is rapid in the first several minutes. Then, they are slowed down until the desorption approached completion, and the desorption attains equilibrium in $200 \mathrm{~min}$ at an agitation speed of $100 \mathrm{rpm}$. The desorption capability was slightly affected by the contact time of adsorption in the $0.5-24 \mathrm{~h}$ intervals. The percentage of desorption was higher than $90 \%$ at $200 \mathrm{~min}$. The results indicated that the iron-coated sand could be regenerated by acid solution. According to the research reported by Theis et al. (1988), the slower desorption rate of cadmium from goethite suggests the mechanisms of reaction perhaps involve surface chemical reactivity. Thus, it can be inferred that the desorption reaction of slower rate of copper ions on iron-coated may be attributed to one or more additional mechanisms such as surface chemical reactivity. Results are in agreement with Jain and Ram (1997) who reported that lead and zinc ions were adsorbed on bed sediments of the river. It is attributed to a very slow diffusion of the adsorbed metals from the surface film into the micropores which are the least accessible sites of adsorption.

Besides, for the application envisioned, the longevity of the iron-coated sand was dependent on its ability to withstand exposure to mild acid solution. The ironcoated sand was exposed to $\mathrm{pH}=2.0$ and $3.0 \mathrm{HNO}_{3}$ solution for $2 \mathrm{~h}$, the soluble iron was approximately $1.1 \%$ and $0 \%$, respectively. Therefore, the solution $\mathrm{pH}$ should be concerned for the regeneration of iron-coated sand in the future.

\subsection{Specific surface area and pore size distribution analyses}

Surface areas and pore size distribution for the samples were investigated using BET analysis. Specific

Table 1

Adsorption density of copper in various concentration on $2.5 \mathrm{~g}$ iron-coated sand under $\mathrm{pH}=6.0, \mathrm{NaNO}=0.1 \mathrm{~N}$

\begin{tabular}{lcccccc}
\hline & Run 1 & Run 2 & Run 3 & Run 4 & Run 5 & Run 6 \\
\hline Initial concentration $(\mathrm{mg} / \mathrm{l})$ & 4.76 & 6.28 & 15.61 & 31.42 & 47.63 & 62.43 \\
Equilibrium concentration $(\mathrm{mg} / \mathrm{l})$ & 0.26 & 0.50 & 5.00 & 17.21 & 29.82 & 40.42 \\
Adsorbed density $(\mu \mathrm{g}-\mathrm{Cu} / \mathrm{g}$-sand) & 45.0 & 57.8 & 106.1 & 142.1 & 178.1 & 220.1 \\
\hline
\end{tabular}

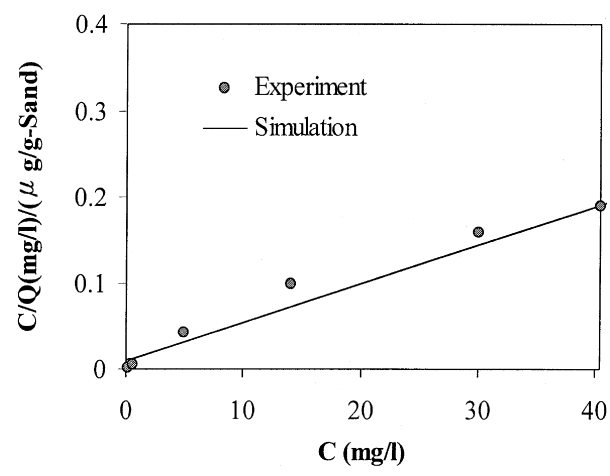

Fig. 4. Experimental and simulated data by Langmuir equation for copper adsorbing in various concentration under $\mathrm{NaNO}_{3}=$ $0.1 \mathrm{~N}, \mathrm{pH}=6.0$.

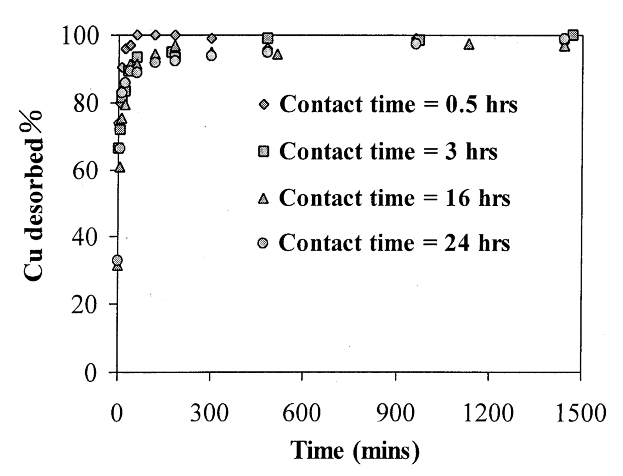

Fig. 5. The desorption rate for copper on $2.5 \mathrm{~g}$ iron-coated sand under $\mathrm{pH}=3.0 \mathrm{HNO}_{3}$ solution, adsorption contact time $=0.5-24 \mathrm{~h}$. 
Table 2

Specific surface areas for the quartz sand and various iron-coated sands

\begin{tabular}{lllll}
\hline & Quartz sand $^{\mathrm{a}}$ & Unadsorbed $^{\mathrm{b}}$ & Adsorbed $^{\mathrm{c}}$ & Desorbed $^{\mathrm{d}}$ \\
\hline Surface areas $\left(\mathrm{m}^{2} / \mathrm{g}\right.$-sand $)$ & 0.85 & 2.76 & 1.67 & 2.82 \\
\hline${ }^{\mathrm{a}}$ Uncoated sand. & & & & \\
${ }^{\mathrm{b}}$ Without reacting with copper ions. & & & \\
${ }^{\mathrm{c}}$ After reacting with copper ions. & & & \\
${ }^{\mathrm{d}}$ After soaking with $\mathrm{pH}=3.0$ acid solution. & & &
\end{tabular}

surface areas for the quartz sand and various ironcoated sands are listed in Table 2. The pore volume and pore size distributions for various iron-coated sands under unadsorbed, adsorbed and desorbed copper ions are summarised in Fig. 6, respectively. The pore size distributions were calculated using the Dubinin-Radushkevich Stoeckli (DRS) (Dubinin and Stoeckli, 1980) equation for adsorbents with heterogeneous micropore size distributions. The ordinate shows the differential change in total volume $(V)$ with pore size $(D)$. Pore size distributions of freshly unadsorbed iron-coated sand were all less than $1200 \AA$, including mesopores (diametre 20-500 ̊) and micropores (diametre $<20 \AA$ ). However,

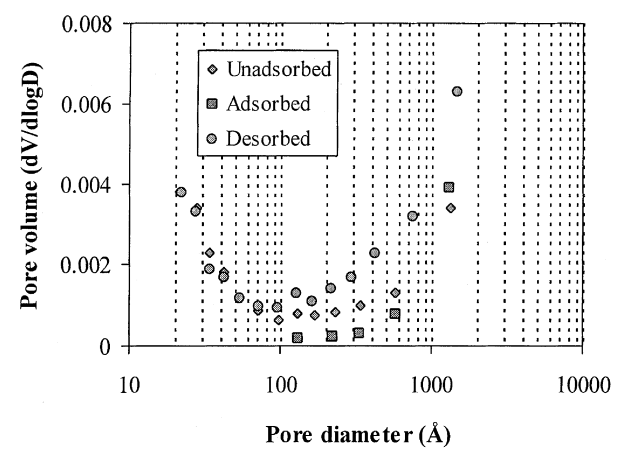

Fig. 6. The pore volume and pore size distributions for various iron-coated sands under unadsorbed, adsorbed and desorbed copper ions. the pore size distribution of iron-coated sand had been changed after reacting with copper ions, thus, parts of pores (diametre $<120 \AA$ ) disappeared through the adsorption process. The results indicated that the micropores and parts of mesopores (diametre $<120 \AA$ ) were occupied with copper ions. At the mean time, surface area of the adsorbed iron-coated sand decreased from 2.76 to $1.67 \mathrm{~m}^{2} / \mathrm{g}$-sand after reacting with copper ions. Besides, pore size distribution of desorbed ironcoated sand was similar to that of unadsorbed ironcoated sand. Micropores and mesopores (diametre $<120 \AA$ ) appeared again, while the surface area increased from 1.67 to $2.82 \mathrm{~m}^{2} / \mathrm{g}$-sand. This was consistent with the surface area of freshly unadsorbed iron-coated sand. The results indicated copper ions could be desorbed from the surface sites of micropore and mesopores (diametre $<120 \AA$ ) by the regeneration of soaking with acid solution. Pore size distributions analyses therefore provided the direct evidence for the results observed in Fig. 5 and the supporting evidence for the slower desorption rate of copper ions from iron-coated sand suggested the mechanisms of reaction involved pores diffusion and chemical reactivity.

\subsection{SEM/EDAX analysis}

If the solid sample of iron-coated sand causes a change of elemental constitution through adsorption reaction, it can be inferred that iron oxide has already
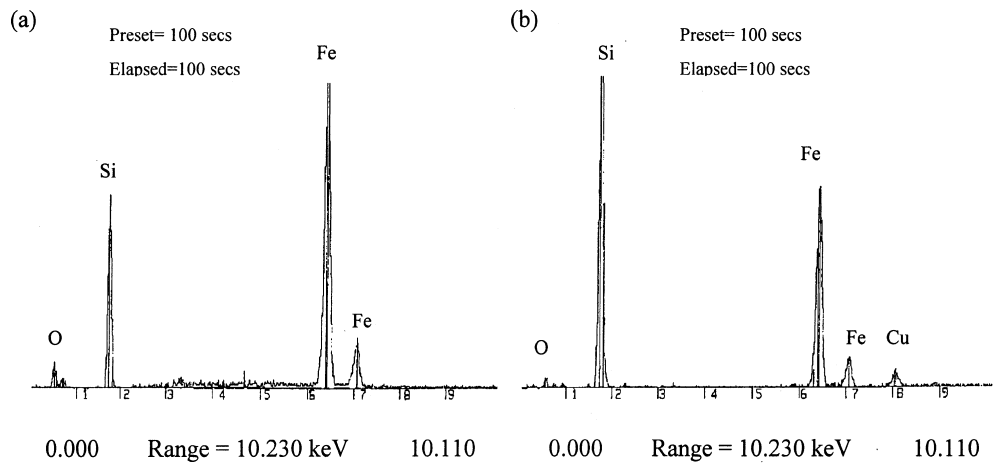

Fig. 7. EDAX spectrum of iron-coated sand under: (a) adsorbed without copper ion, $\mathrm{NaNO}_{3}=0.1 \mathrm{~N}$, $\mathrm{pH}=5.5$; (b) adsorbed copper ions: $\mathrm{Cu}_{(\mathrm{t})}=64 \mathrm{mg} / \mathrm{l}, \mathrm{pH}=5.5$. 
brought about chemical interaction with adsorbate. Physical adsorption of ions is unable to remain on solid surface through complete elution process. The spectrum of eluted iron-coated sand by using elemental microprobe analysis of SEM/EDAX is illustrated in Fig. 7. Only $\mathrm{Fe}, \mathrm{Si}$ and $\mathrm{O}$ signals can be observed in Fig. 7(a) which have been known as the principal elements of freeze-dried samples of iron-coated sand without copper. Though a high level of background electrolyte $\mathrm{NaNO}_{3}$ was in aqueous phase, no signals of $\mathrm{N}$ and $\mathrm{Na}$ were found in this spectrum. Therefore, it can be indicated that nonspecific adsorption of ions $\left(\mathrm{Na}^{+}\right.$and $\mathrm{NO}_{3}^{-}$) is unable to exist on the surface of iron-coated sand through complete elution process. The EDAX spectrum for copper system is illustrated in Fig. 8. The result shows that copper becomes the principal element of the solid sample except $\mathrm{Fe}, \mathrm{Si}$ and no $\mathrm{N}$ and $\mathrm{Na}$ signals are detected in this spectrum. This was due to the fact that copper ions were chemisorbed on the surface of iron-coated sand. EDAX analysis therefore provides the direct evidence for specific adsorption of copper ions on the surface of iron-coated sand. These results are similar with the previously reported by Hsia et al. (1993) who indicated that chromate was chemisorbed onto iron oxide surface.

Besides, the elemental concentration distribution of solid sample can be analysed using the mapping analysis of SEM/EDAX. The elemental distribution mapping of EDAX for the sample of iron-coated sand reacting with copper ions is illustrated in Fig. 8. The bright points represented the signal of copper element from the solid sample. Copper were spread over the surfaces of ironcoated sand. Results indicated that iron oxide produces chemical bond with copper ions. Thus, copper element was a constituent part of the solid sample.

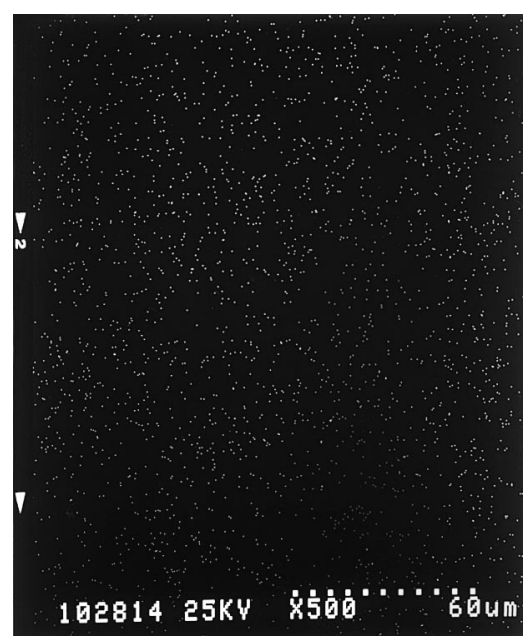

Fig. 8. Mapping EDAX analysis of $\mathrm{Cu}$ element for iron-coated sand under $\mathrm{Cu}_{(\mathrm{t})}=64 \mathrm{mg} / \mathrm{l}, \mathrm{pH}=5.5$.

\section{Conclusions}

Results of this research develop an innovative technology to coat iron oxides on sand surfaces, and use for metal ions removal from water. The iron-coated sand had more micropores and higher specific surface area because of the attachment of iron oxides, and copper ions could be adsorbed efficiently by the iron-coated sand from water. Copper ions could penetrate into the micropores and mesopores of iron oxides on the sand surfaces, and the regeneration of the iron-coated sand could be achieved by soaking with $\mathrm{pH}=3.0$ acid solution. Adsorption behaviours of copper ions on the ironcoated sand included pores diffusion and chemical reactivity. The iron-coated sand has potentially suitable for applying to a packed bed for the treatment of heavy metal from water.

\section{Acknowledgements}

The authors express their gratitude to the National Science Council, Taiwan, for its financial support (Contract No: NSC 88-2621-E-242-003).

\section{References}

Bailey, R.P., Bennett, T., Benjamin, M.M., 1992. Sorption onto and recovery of $\mathrm{Cr}(\mathrm{IV})$ using iron-oxide-coated sand. Wat. Sci. Tech. 26 (5-6), 1239-1244.

Benjamin, M.M., Leckie, J.O., 1981. Multiple site adsorption of $\mathrm{Cd}, \mathrm{Cu}, \mathrm{Zn}$ and $\mathrm{Pb}$ on amorphous iron oxyhydroxide. Colloid Interface Sci. 79, 209-215.

Benjamin, M.M., Sletten, R.S., Bailey, R.P., Bennett, T., 1996. Sorption and filtration of metals using iron-oxide-coated sand. Wat. Res. 30 (11), 2609-2619.

Dubinin, M.M., Stoeckli, H.F., 1980. Homogeneous and heterogeneous micropore structures in carbonaceous adsorbents. J. Colloid Interface Sci. 75 (1), 34-42.

Edwards, M., Benjamin, M.M., 1989. Adsorptive filtration using coated sand: a new approach for treatment of metalbearing wastes. J. WPCF 61 (9), 1523-1533.

Hsia, T.H., Lo, S.L., Lin, C.F., Lee, D.Y., 1993. Chemical and spectroscopic evidence for specific adsorption of chromate on hydrous iron oxide. Chemosphere 26, 1897-1904.

Jain, C.K., Ram, D., 1997. Adsorption of lead and zinc on bed sediments of the river kali. Wat. Res. 31 (1), 154-162.

Lai, C.H., Lo, S.L., Lin, C.F., 1994a. Evaluating an iron-coated sand for removing copper from water. Wat. Sci. Tech. 30 (9), 175-182.

Lai, C.H., Lo, S.L., Lin, C.F., 1994b. Mechanisms of iron oxide coating onto sand surface and its adsorption behavior for copper. Toxicol. Environ. Chem. 46, 107-118.

Lo, S.L., Jeng, H.T., Lai, C.H., 1997. Characteristics and adsorption properties of iron-coated sand. Wat. Sci. Tech. 35 (7), 63-70. 
Satpathy, J.K., Chaudhuri, M., 1995. Treatment of cadmiumplating and chromium-plating wastes by iron oxide-coated sand. Water Environ. Res. 67 (5), 788-790.

Schwertmann, U., Taylor, R.M., 1989. Iron oxides. In: Dixon, J.B., Weed S.B., (Eds.), Minerals in Soil Environments, second ed., Soil Sci. Soc. Am. J. Madison, Wisconsin, USA, pp. $379-428$.
Theis, T.L., Iyer, R., Ellis, S.K., 1992. Evaluating a new granular iron oxide for removing lead from drinking water. J. AWWA 84, 101-105.

Theis, T.L., Iyer, R., Kaul, L.W., 1988. Kinetics studies of cadmium and ferricyanide adsorption on goethite. Environ. Sci. Technol. 22, 1013-1017. 